\title{
Cognitive development in ICT contexts
}

\author{
Pamela Gibbons, Kathryn Crawford, Susan Crichton and Robert Fitzgerald \\ Australian Catholic University, PO Box 968, North Sydney, NSW 2059, Australia. \\ p.gibbons@mackillop.acu.edu.au \\ University of Sydney, Australia \\ School District \#10, British Columbia, Canada \\ Australian Catholic University, Australia.
}

Keywords: cognition, context, individual differences, designing learning environments

\begin{abstract}
New, dynamic, virtual learning environments are presenting opportunities for more diverse types of learning and cognitive social activity than have been previously available in formal educational settings. Some consequences of our understanding of how learning occurs include newly recognised forms of learning, how these can be nurtured, and how this new knowledge can be applied to the design of virtual social contexts that encourage new approaches to learning and thinking. Also, settings in which ICT are used can be designed in new ways to take advantage of the knowledge that cognition is plastic, active and socially embedded. In this paper, four related investigations are presented which are based on systemic, socio-cultural approaches to the understanding of learning in ICT contexts. Our research indicates, however, that there is also a need for changes in institutional practice if these new approaches are to be actualised.
\end{abstract}

\section{INTRODUCTION}

New dynamic virtual learning environments are presenting opportunities for more diverse types of learning and cognitive social activity than have been previously available in formal educational settings. One consequence of our understanding of how learning occurs is that newly recognised forms of learning can be nurtured. It is also now possible to apply our knowledge of learning to the design of virtual social contexts that encourage new approaches to learning and thinking. A second consequence of our understanding of how learning occurs is that settings in which information

The original version of this chapter was revised: The copyright line was incorrect. This has been corrected. The Erratum to this chapter is available at DOI: 10.1007/978-0-387-35499-6_29 
and communication technologies (ICT) are used can be designed in new ways. That is, the social practices and physical design of settings in which humans learn can be designed to take advantage of the knowledge that cognition is plastic, active and socially embedded. Our research indicates, however, that there is also a need for changes in institutional practice if these new approaches are to be actualised.

In this paper, a range of research-based perspectives on the dynamics of learning in ICT-rich contexts is presented. Merleau-Ponty (1962) showed that our knowledge is dependent on being in a world that cannot be separated from our body, our language or our socio-historical settings. This embodied or emergent view suggests that meaning has its origin in the activity of the semi-autonomous agent and recognises the fundamental plasticity of cognition. Emerging neuro-evolutionary views such as the Theory of Neuronal Group Selection (TNGS) (Edelman and Tononi 1995) also entertain the plasticity of cortical function at the level of neuronal groupings and consider perception as an active and creative act. Sociocultural theorists (Luria 1973; Vygotsky 1978; Crawford 1996) recognise the plastic and active form of higher psychological function. While important work has been done on the situated (Lave and Wenger 1991) and distributed (Hutchins 1995) nature of cognition, both of these approaches tend to marginalise the activity of the thinking subject (Nardi 1996) and the role of individual differences in cognitive function. The real challenge for research is to investigate individual difference constructs within situated human activity frameworks that entertain the dynamic relationship between learner and context. Systemic, socio-cultural approaches to the understanding of learning in context therefore form the basis of the explorations discussed herein.

The first study presented explores the development of a practice-based model of cognitive style for studying the interaction between individual learners and context. This research suggests that cognition and context are not closed independent systems but rather open-ended and dialogic. The second study, also investigating individual differences in cognitive style in an ICT context, proposes the exploitation of such knowledge to design computer programming learning environments which actively encourage the development of those cognitive abilities which are required to progress to intermediate and advanced programming.

The last two studies investigate the above themes at a more 'macro' level, that is, that of institutions. The third study reports a three-year study of online learning in which data support the notion of an inter-relationship between the institutional contexts and instructional design and practice. The final study investigates informal learning by staff in a university setting. The data confirm the strong positive relationships between individual agency 
involving conceptions of technology, personal visions and goals of future uses of technology and emerging capabilities. The implications for the design of workplace practices to support learning and development are discussed.

\section{DESIGNED INTERACTIONS: TECHNOLOGY AND LEARNERS}

Luria's integrative work on the brain (1973), still well regarded in contemporary neuropsychology (Goldberg 1990), provides the theoretical foundation for a model of cognitive style that underpins this study. Luria identified two different types of intellectual activity: simultaneous processing (involving the organisation of discrete elements into an integrated group or whole) and successive processing (involving the ordering or chaining of successively arriving elements). An executive control function has also been identified. In the study reported herein, two groups of learners were selected on the basis of an identified marked asymmetry with respect to their levels of simultaneous and successive processing, it being hypothesised that a strong stylistic approach would be evident for these groups. One characterisation of these two groups is as procedural (successive) and relational (simultaneous) thinkers. It is important to note that these models are conceptual and are used as objects to think about cognitive practice.

Integrated Learning Systems (ILS) are computer-based systems that manage the delivery and evaluation of instruction. A recent evaluation of an ILS found that procedural/verbal thinkers gained more per unit time than relational/visual thinkers on computer-based mathematics and reading tasks $(\mathrm{F}(3,62)=4.55, \mathrm{p}<.006$, effect size $=.18)$ suggesting the instructional design of the system was better matched to procedural/verbal thinkers (Fitzgerald, Hughes and Fitzgerald 1996).

This research also explored the possibility of 'situated interventionism' with the aim of "creating new forms of practices" (Engestrom and Cole 1997:308) by manipulating the setting of children's problem solving. One setting was developed to be more open-ended and relational requiring children to solve co-variation problems by trying to find the 'pattern'. The other setting was more closed and rule-based requiring children to solve similar problems by closely following the instruction they had been given. The data showed interesting context effects suggesting procedural thinkers worked better in the rule-based settings $(F=2.542, p=.058)$ whereas there was no context effect for relational thinkers. There were also strong suggestions from the data that children could describe their problem solving in more complex and sophisticated ways in open and relational settings. 
This study demonstrated the utility of this practice-based model of cognitive style for studying the interaction between learner and context. We have seen that cognition and context are not closed, independent systems but are fundamentally dialogic, open-ended and directed towards the future. We have also seen that with knowledge of cognitive style it is possible to manipulate contexts in ways that can make new practices possible. Beginning with an analysis of individual differences, this research strongly suggests the importance of moving beyond the solitary thinker to consider their dialogical engagement with the world and offers a glimpsed potential for a better understanding of designed interactions.

\section{PROGRAMMING CONTEXTS FOR THE DEVELOPMENT OF COGNITIVE ABILITIES}

Also grounded in the work of Luria (1973), this study explored the proposition that the development of mental models of recursion is profoundly influenced, in product and in process, by the simultaneous and successive processing abilities of individual learners (Gibbons 1995). Five case study subjects with specific asymmetric cognitive profiles were drawn from the population. Whilst controlling for the executive control function, subjects were selected on the basis of asymmetric high/low, low/high and high/high simultaneous and successive processing profiles.

Differences in simultaneous and successive processing abilities were observed to be associated with differences in motivation, problem perception, strategy development, selection of tactics, implementation activity, solution discovery, and self-assessment of performance. From this study it has been possible to identify a number of critical factors in the design of computer programming environments that encourage the development of simultaneous processing abilities which are, in turn, crucial to the progression of learner-programmers to more advanced levels of programming.

It was observed that the satisfactory accomplishment of trivial programming tasks through attention to procedural detail contributes to the persistence of successive strategies in the absence of tasks which, unlike recursion, demand simultaneous processing. As high successive learners progress to attempt more complex tasks in novel situations, the likelihood of successful task solution diminishes; this is exacerbated by the reliance of early successes on successive strategies and the resultant reluctance to abandon such strategies. The non-systematicity of high successive learners' conceptualisation may result in their failure to ultimately progress to the development of a sound understanding of complex constructs and their longterm manifestation of cognitive activity typically associated with novices. 
The notion of the plasticity of cognitive abilities is therefore supported by this observation that, without the setting of tasks which demand the invocation of simultaneous processing, successive abilities will progressively improve, by default and without deliberate intervention, at the expense of simultaneous abilities.

Knowledge of differences in component cognitive abilities can provide a basis for the informed structuring of collaborative programming teams. Whilst some learners may be capable of individually invoking the concerted activity of simultaneous and successive processing abilities, others may fully realise their potential only in concerted collaboration with others of complementary cognitive profile. The provision of systemic programming supports, i.e. cognitive artefacts (Norman 1991), to supplement simultaneous or successive abilities would serve a similar function and facilitate the realisation of the computer as a collaborator.

\section{VIRTUAL ENVIRONMENTS TO SUPPORT LEARNING}

This research represents a case study of three years of actual practice of participants in one online educational programme. It was located online in a computer conference hosted by the British Columbia Ministry of Education and the Open Learning Agency - The New Directions in Distance Learning programme (NDDL). Participants communicated via an electronic conference and email system, and instruction was supported with audiographic conferences. It was an expectation of the project and an assumption of the initial research design that a rich community of learners would form online. However, what emerged from the research was the realisation that the organisational structure of the educational programme had a substantial affect on the learning potential, becoming as much of an artefact for the participants as the technology and the curriculum.

Developed from this research is a theoretical model of an organisation for learning, informed by action and intentional learning. This design recognises that the organisation into which an innovation is placed is a critical variable in the adoption of the innovation. Three attributes of an organisation for learning were identified: personal mastery (individual activity), social interaction (collaboration), and systems thinking (holistic understanding). The model developed from this research suggests that any learning activities, especially those existing in lean, socially impoverished environments such as cyberspace (Walther and Burgoon 1992), must incorporate opportunities to develop personal mastery, social interaction, and systems thinking into their designs. The assumption that those three attributes might be inherent in a model was found not true in this case study. 
If virtual learning environments are to support higher order thinking, designers and educators must consciously build the three attributes of organisations for learning into the model. Activity Theory must be incorporated into the school experience, allowing all learners (students and educators) to grapple with activities to develop personal understanding and demonstrate learning, allowing schools to develop as organisations for learning.

Most notable in this research was the effect that the organisational structure had on the participants' ability to maintain the virtual communication network. While there were many confounding variables that appeared to affect online communication, the organisational structure (size, developed hierarchy, increased bureaucracy, etc.) was identified as having a major impact and, over time, was able to modify an innovative instructional design, which utilised most of the promises of computer-supported conferencing, and return it to the traditional design of direct instruction.

\section{LEARNING AND INFORMATION TECHNOLOGIES IN CONTEXT}

The fourth study describes research which was carried out at the University of Sydney (Crawford and Crawford 1997) to investigate the factors influencing emerging conceptions, capabilities and patterns of use across several disciplines and in the administrative sector. The project aimed to elicit information about:

- staff conceptions of the opportunities and constraints of the university context with respect to ICT;

- the impact of job definitions and role expectations on the use of ICT;

- staff access to and use of ICT at work and at home;

- the relationships between these variables.

The research identified strong positive relationships between individual agency, evolving conceptions of ICT, personal vision and goals for future use of ICT and emerging operational capabilities in the use of ICT. There were wide differences in access to and use of ICT at work and at home. Earlier indications of the impact of differing local contexts on emerging conceptions and capabilities were also confirmed. There were marked differences between groups in capabilities, conceptions and patterns of use.

The data indicated that emerging operational capabilities in the use of ICT and frequency of use were positively associated with:

- the reported agency of subjects, i.e. the extent that they felt able to act independently to resolve problems and make change;

- the extent that subjects had a positive personal vision of their future involving the use of ICT. 
High levels of agency and a personal vision of a changed future involving the use of ICT were positively associated with workplace settings where:

- personal or group agency and independent action were rewarded (e.g. research);

- there was consensus about the functionality of new technologies in the valued activities of the group (e.g. role of ICT in discipline-based activities);

- group (i.e. department or section) identity and goals for future activity included the use of ICT.

- Capabilities and conceptions were negatively associated with:

- highly regulated contexts (e.g. administration);

- feelings of distress about change;

- feelings of lack of time.

The last two factors were positively associated with age, years of employment at the university and level of employment. They also appear to be associated with a persistence of well established operational (successive) strategies that are unquestioned and sustained even when it is obvious that they are not strategic in the new situation. This result is similar the behaviour of successively oriented programmers described above. Within the university setting, personal agency was clearly used in two opposing ways according to individual conceptions of strategic action:

- to resist changes associated with ICT;

- to enhance communication, co-operation and the use of ICT in research and administration.

This research supports Wenger's (1998) assertion that people occupy multiple roles in multiple communities and their learning and their activity in each role are influenced by the dynamics of the particular context. Within a large organisation such as a university, informal learning is influenced substantially by the socio-cultural rules, roles and conceptions of staff and these in turn are influenced by localised conditions with variation from group to group and according to ascribed roles within each group. In the sample, people appeared to respond strategically in different ways according to the socio-political contexts in which they worked. These different responses were associated with differing conceptions of, and operational capabilities associated with, ICT.

\section{6.}

\section{SYNTHESIS AND CONCLUSION}

The first study observed that to better realise the new opportunities offered by technology we need to develop more reflexive theoretical accounts of learners acting in contexts of practice. Studying technology-rich 
environments in the context of cognitive style has allowed us to recognise dimensions of the interaction between learner and context and with this knowledge act to design future interactions. Similarly, the second study, in proposing the design of learning environments to foster complementary collaboration, not only recognises, but seeks to actively exploit, the intellectual richness afforded by the social distribution of knowledge and cognition between individuals and artefacts.

The latter two studies extended these propositions into institutional contexts revealing the crucial role of social settings in affecting the outcomes of designed learning environments. The third study discovered that, even when using leading edge telecommunications technology in an attempt to move beyond the traditional direct instruction model typically found in most educational institutions, the structure of the learning environment was not consistent with the attributes required to support knowledge-building. The organisational structure of the institution, itself, was found to have the potential to limit innovative practice and replace it with the traditional methods even when there had been an attempt to modify these methods through the use of new technologies in the first place. The last study supports the notion that the dialogic relationship between people and technology is strategic and personal. Capabilities and frequency of use of the ICT environment were positively associated with personal identity, goals and relationships with the institutional arena that were consistent with learning informally in order to accomplish meaningful goals through strategic use of technology.

The fourth study also supported the observation that there is a need for changes in institutional practice if new approaches to learning with ICT, and working with ICT, are to be realised. New technologies offer the possibility of changes in the scope and distribution of human activity and experience. In any place where people work together, however, learning how to integrate new technologies productively with day to day activities, often with their origins in a previous age, is a major challenge.

From these studies we now recognise:

- the diversity of contexts and human responses in educational settings;

- that learning contexts are socio-politically situated but always open to change;

- the plastic, active and socially-embedded nature of cognition;

- dialogic and personal inter-relations between context and cognition and related knowledge and capabilities;

- that learning is a natural lifelong process when adaptation to novel situations is necessary. 
In the future, we are interested in developing theories which take into account the dynamics of the fluid interaction from which individual and group knowledge and capabilities emerge.

\section{REFERENCES}

Crawford, K. and Crawford, S. (1997) Agency, technology and vision: The dynamics of learning. Sydney: The University of Sydney.

Crawford, K. (1996) Vygoskian approaches to human development in the information era. Educational Studies in Mathematics 31(1-2) 43-62.

Edelman, G.M. and Tononi, G. (1995) Neural Darwinism: The brain as a selectional system. In J. Cornwall (ed.) Nature's imagination. Oxford: Oxford University Press.

Engestrom, Y. and Cole, M. (1997) Situated cognition in search of an agenda. In D. Kirshner and J.A. Whitson (eds.) Situated cognition: Social, semiotic and psychological perspectives. New Jersey: Lawrence Erlbaum.

Fitzgerald, D., Hughes, P., and Fitzgerald, R.N. (1996) An evaluation of computer assisted learning in Victorian schools. Research Monograph. Melbourne: Victorian Directorate of School Education. [http://www.sofweb.vic.edu.au/lt/cal_eval.htm]

Gibbons, P. (1995) A cognitive processing account of individual differences in novice Logo programmers' conceptualisation and use of recursion. Journal of Educational Computing Research 13(3) 211-226.

Goldberg, E. (1990) Contemporary neuropsychology and the legacy of Luria. New Jersey: Lawrence Erlbaum.

Hutchins, E. (1995) Cognition in the wild. Cambridge, MA: MIT Press.

Lave, J. and Wenger, E. (1991) Situated learning: Legitimate peripheral participation. Melbourne: Cambridge University Press.

Luria, A.R. (1973) The working brain: An introduction to neuropsychology. Middlesex: Penguin.

Merleau-Ponty, M. (1962) Phenomenology of perception. Evanston, IL: Northwestern University Press.

Nardi, B. (1996) Studying context. In B. Nardi (ed.) Context and consciousness. Cambridge MA: MIT Press.

Norman, D. A. (1991). Cognitive artefacts. In J. M. Carroll (ed.) Designing interaction: Psychological theory at the human-computer interface. Cambridge, MA: Cambridge University Press.

Vygotsky, L. (1978) Mind in society. Cambridge, MA: Harvard University Press.

Walther, J. B. and Burgoon, J. K. (1992) Relational communications in computer-mediated interaction. Human Communications Research 19(1) 50-88.

Wenger, E. (1998). Communities of practice. Cambridge, MA: Cambridge University Press.

\section{BIOGRAPHIES}

Pamela Gibbons is currently the Head of the School of Business and Informatics (NSW) at Australian Catholic University, based at North Sydney. Her doctoral studies focused on individual differences in cognitive abilities as they relate to students' learning of computer programming. 
Kathryn Crawford is a Senior Lecturer in the Faculty of Education at the University of Sydney and also directs the Novae Research Group at the Australian Technology Park. She is interested in investigating the social dimensions of technology-based learning with particular regard to better understanding the fluid dynamics between learner and artefacts.

Susan Crichton works in Schools District \#10, British Columbia, Canada where she has been involved the design and evaluation of online education programmes for students living in remote regions. Her current research interests include the investigation of 'screen literacy'.

Robert Fitzgerald lectures at Australian Catholic University, based in the Faculty of Education at Signadou Campus, Canberra. His current research interest lies in exploring the ability of teachers to design technology-rich learning environments to facilitate the development of newly recognised forms of learning.

In the future, this group hopes to continue their collaboration on sociocultural approaches to the study of learning in information and communication technology contexts. It is expected that the work of Luria and Vygotsky will continue to underpin their development of theories relating to situated cognition and the centrality of socio-cultural contexts in ICT learning environments. 